\title{
The effects of contrast upon compliance with socially undesirable requests in the foot-in-the-door paradigm
}

\author{
MITRI E. SHANAB and STEVEN A. ISONIO \\ California State University, Fresno, California 93740
}

\begin{abstract}
The study sought to assess the effects of the degree of contrast between the initial and critical requests upon the rate of compliance in the foot-in-the-door paradigm. Subjects were randomly assigned to a high-contrast, low-contrast, or no-initial-request control condition. The critical request was presented either immediately or after an average of 8.5 days. It was found that the timing of the critical request failed to affect the rate of compliance. However, subjects in the low-contrast condition complied at a significantly higher rate than those in the highcontrast condition, although neither of the experimental conditions differed significantly from the control condition. The latter finding was discussed in terms of the inhibitory role of contrast upon compliance in the foot-in-the-door paradigm.
\end{abstract}

Of the many techniques that have been shown to induce compliance, two have received more attention than the others. In both of these techniques, a moderatesized critical request with which compliance is actually desired is preceded by either a small request, in the case of the foot-in-the-door technique, or a fairly large and unreasonable request, in the case of the door-in-theface technique.

The most commonly accepted explanation of the effectiveness of the foot-in-the-door technique has been Bem's (1972) self-perception theory, which states that people infer their internal states by observing their overt behavior. Thus, in the foot-in-the-door situation, subjects who comply with the small initial request come to see themselves as "compliers" and, therefore, would be more likely to comply with the critical request. There is some evidence in the literature, however, that strongly suggests that contrast rather than self-perception may be involved in studies using the foot-in-the-door technique. Seligman, Bush, and Kirsch (1976) and, more recently, Shanab and O'Neill (1982) found that if the initial request was very small, the foot-in-the-door technique failed to induce compliance. In the study by Seligman et al. (1976), subjects presented with an initial request that was only slightly smaller than the critical request complied with the critical request at a higher rate than those presented with initial requests that were either moderately or extremely smaller than the critical request. That is, higher rates of compliance were obtained when the amount of contrast between the two was minimal, and lower rates of compliance were obtained with greater

Portions of this paper were presented by the second author at the 62nd annual convention of the Western Psychological Association, April 9, 1982. Reprint requests should be mailed to Mitri E. Shanab, Department of Psychology, California State University, Fresno, California 93740. degrees of contrast. Shanab and O'Neill (1982), using socially undesirable requests, reported significantly more compliance when the critical request was preceded by a small initial request than when it was preceded by a very small initial request. We have proposed that when the initial request is very small and the subject consents, the critical request, by comparison, looks much larger than it actually is, leading the subject to reject the critical request. Thus, it appears that in order to induce compliance in the foot-in-the-door technique, the degree of contrast between the two requests must be minimal. That is, the small size of the first request should be such that the second request will not be perceived as appreciably larger than it is.

Additional evidence based on the door-in-the-face technique also suggests that contrast affects the rate of compliance. Cialdini, Vincent, Lewis, Catalan, Wheeler, and Darby (1975) showed that subjects complied with a moderate-sized critical request that was preceded by a large and unreasonable request at a higher rate than control subjects who were presented with the critical request only. Cialdini et al. (1975) explained this effect in terms of Gouldner's (1960) norm-of-reciprocity model, which holds that there is a tendency for persons to reciprocate favors and concessions. Specifically, Cialdini et al. (1975) have proposed that the critical request is seen as a concession on the part of the requester, and therefore, the subject feels somewhat pressured to reciprocate, namely, by complying with the second request.

Miller, Seligman, Clark, and Bush (1976) have argued that the effectiveness of the door-in-the-face technique is due to the fact that the unreasonable first request serves as an anchor against which the critical request is compared. Thus the critical request appears smaller and more reasonable than it actually is. Miller et al. showed that the critical factor inducing compliance was the 
perceived contrast between the initial request and the critical request rather than a tendency on the part of the subjects to respond to what they perceived to be a concession by the experimenter. Using socially undesirable requests in a replication of Miller et al.'s design, Shanab and O'Neill (1979) also showed that the critical determinant of compliance was the perceived contrast between the initial unreasonable request and the less demanding critical request. Later, Shanab and Isonio (1980), using essentially the same design, found that when a delay period of 7-10 days was inserted between the initial and critical requests, no significant compliance was observed, presumably because contrast was diminished over the delay interval. Finally, Shanab and O'Neill (1982) obtained a significantly higher rate of compliance when the initial request was very large than when it was reasonably large.

The purpose of the present study was to compare the efficacy of the contrast and self-perception explanations of the foot-in-the-door phenomenon. Contrast was manipulated directly by changing the species to be punished and the modality of punishment between the initial and critical requests, and indirectly by introducing the critical request for half of the subjects after a delay period. A 3 by 2 factorial design was used that combined degree of contrast (low, high, and none) and the timing of the second request (immediate and delayed).

Since the initial request in both the high- and lowcontrast conditions is small, a high degree of compliance with the first request would be expected. According to the self-perception theory, subjects in both the high- and low-contrast groups should show a higher rate of compliance with the critical request than their controls. However, according to the perceptual contrast interpretation, although subjects in the high-contrast condition would be expected to show less compliance than those in the low-contrast condition, they should also show no increase in compliance relative to their controls. If the manipulation is effective, subjects in the low-contrast group should show greater compliance than their controls.

\section{METHOD}

\section{Design}

A 3 by 2 factorial design combining amount of contrast (high, low, and none) and timing of the second request (delayed or not delayed) was used.

\section{Subjects}

Subjects were 120 students from introductory psychology classes at California State University, Fresno. They were randomly assigned to the six experimental conditions. The data of one subject from each of the delayed control and nondelayed low-contrast conditions and two subjects from the delayed control condition were eliminated because postexperimental inquiry revealed that these subjects were not naive.

\section{Procedure}

Upon arrival at the experimental room, each subject was greeted by the experimenter, seated, and handed a booklet with two lists of words and anagrams. The experimenter then asked each subject to rate the items on the lists in terms of how pleasant or unpleasant they sounded. After the subjects completed this cover task, the requests were made.

The initial request for subjects in the low-contrast condition involved asking them if they were willing to participate in an experiment requiring 15 min of their time; their main task would be to punish human subjects by deducting points whenever they made errors in a paired associate task. The initial request in the high-contrast condition consisted of asking subjects to participate in a 15 -min study in which they would be sounding a loud buzzer as punishment for rats whenever the rats made errors in a discrimination task. The critical request, which was presented to all subjects, involved a single 1-h session during which the subjects' main task was to administer punishment in the form of electric shock to human subjects whenever they made errors in a paired associate task. The subjects in the nondelayed conditions were presented with both the initial and critical requests during one session. Those subjects in the delayed condition were presented with the first request in one session and were asked to return 7-10 days later, presumably in order to receive the results of the ratings task, when they were actually presented with the second request as well.

\section{RESULTS AND DISCUSSION}

As can be seen in Table 1, the delay variable did not have a significant effect $\left[\chi^{2}(6)=5.81, \mathrm{p}>.05\right]$. Collapsing across the delay condition, it was found that subjects in the high contrast condition rejected the critical request at a significantly higher rate than those in the low-contrast condition $\left[\chi^{2}(1)=3.93, p<.05\right]$, but neither the high-contrast nor the low-contrast condition differed from the control condition $\left[\chi^{2}(1) \leqslant 1\right.$ and $\left.\chi^{2}(1)=1.26, p>.05\right]$.

The inhibitory effect of contrast upon compliance in the foot-in-the-door paradigm is indicated by the significantly lower rate of compliance in the high-contrast relative to the low-contrast condition. Although the results of the low-contrast condition were in the direction of a successful foot-in-the-door effect, the difference between the low-contrast and control conditions was not statistically significant. As expected, the highcontrast subjects did not differ from their controls and actually showed less compliance. The absence of an increased compliance in the two contrast conditions relative to the control condition is clearly inconsistent with the self-perception view, especially since the vast majority of the subjects $(83 \%)$ in the contrast groups accepted the initial request.

The failure of the delay variable to affect the rate of compliance in this study was not expected, since in an

Table 1

Frequency (F) and Percent (P) of Compliance as a Function of Amount of Contrast

\begin{tabular}{|c|c|c|c|c|c|c|}
\hline \multirow[b]{2}{*}{ Condition } & \multicolumn{2}{|c|}{ No Delay } & \multicolumn{2}{|c|}{ Delay } & \multicolumn{2}{|c|}{ Combined } \\
\hline & $\mathrm{F}$ & $\mathbf{P}$ & $\mathrm{F}$ & $\mathbf{P}$ & $\mathbf{F}$ & $\mathbf{P}$ \\
\hline High Contrast & 3 & 15.0 & 4 & 20.0 & 7 & 17.5 \\
\hline Control & 5 & 25.0 & 5 & 26.3 & 10 & 25.6 \\
\hline Low Contrast & 6 & 31.5 & 9 & 50.0 & 15 & 40.5 \\
\hline
\end{tabular}


earlier study Shanab and Isonio (1980) found that a delay period inserted between the two requests resulted in the failure of the door-in-the-face technique, presumably because delay reduced contrast. If contrast inhibits compliance in the foot-in-the-door paradigm, then, when it is reduced or eliminated following a delay interval, subjects in the delay condition should comply at a higher rate than those in the no-delay condition. It is possible that the reason for the lack of a significant difference between the delay and nondelay conditions in the present study is a procedural one, which is related in particular to the way in which the critical request was introduced after the delay. The experimenter preceded the critical request with the sentence "As you may recall, I'm working on a research project involving ...." This may have served to remind the subject of the initial request, and, consequently, to restore the contrast between the initial and critical requests.

The results in general seem to favor a perceptual contrast explanation. More specifically, there seems to be an inverse relationship between the amount of contrast present and the rate of compliance obtained in the foot-in-the-door paradigm. Previous studies have indicated a direct relationship between the effectiveness of the door-in-the-face technique and the amount of contrast present. Thus, it appears that both phenomena can be explained parsimoniously by a single process, namely, perceptual contrast. It is proposed that a high degree of contrast inhibits compliance in the foot-inthe-door paradigm but facilitates it in the door-in-theface paradigm. Therefore, when the critical request is preceded by a very small initial request, it will be rejected, but when it is preceded by a moderately small request, it will be accepted. Similarly, the critical request would be accepted if preceded by a very large request and rejected if preceded by a moderately large request.

\section{REFERENCES}

Вем, D. J. Self-perception theory. In L. Berkowitz (Ed.), Advances in experimental social psychology (Vol. 6). New York: Academic Press, 1972.

Cialdini, R. B., Vincent, J. E., Lewis, J. K., Catalan, J., Wheeler, D., \& Darby, B. L. Reciprocal concessions procedure for inducing compliance: The door-in-the-face technique. Journal of Personality and Social Psychology, 1975, 31, 206215.

Gouldner, A. W. The norm of reciprocity: A preliminary statement. American Sociological Review, 1960, 25, 161-178.

Miller, R. L., Seligman, C., Clark, N. T., \& Bush, M. Perceptual contrast versus reciprocal concessions as mediators of induced compliance. Canadian Journal of Behavioral Science, 1976, 8, 401-409.

Seligman, C., Bush, M., \& KIRSCH, K. Relationship between compliance in the foot-in-the-door paradigm and size of first request. Journal of Personality and Social Psychology, 1976, 33, 517-520.

Shanab, M. E., \& Isonio, S. A. The effects of delay upon compliance with socially undesirable requests in the door-in-the-face paradigm. Bulletin of the Psychonomic Society, 1980, 15, 76-78.

Shanab, M. E., \& O'Neill, P. The effects of contrast upon compliance with socially undesirable requests in the door-in-theface paradigm. Canadian Journal of Behavioral Science, 1979, 11, 236-244.

ShaNAB, M. E., \& O'Neill, P. The effects of self-perception and perceptual contrast upon compliance with socially undesirable requests. Bulletin of the Psychonomic Society, 1982, 19, 279 281.

(Received for publication July 29, 1982.) 